\author{
B. $\operatorname{Roy}^{1, *}$, T. Noiri ${ }^{2}$ \\ ${ }^{1}$ Women's Christian College, Kolkata, India \\ ${ }^{2}$ Yatsushiro, Japan \\ (E-mail: bishwambhar_roy@yahoo.co.in,t.noiri@nifty.com)
}

"Dedicated to Professor Filippo CAMMAROTO for his 70th Birthday"

\title{
Applications of operations on generalized topological spaces
}

\begin{abstract}
In this paper, $\gamma_{\mu}$-open sets and $\gamma_{\mu}$-closed sets in a GTS $(X, \mu)$ have been studied, where $\gamma_{\mu}$ is an operation from $\mu$ to $\mathcal{P}(X)$. In general, collection of $\gamma_{\mu}$-open sets is smaller than the collection of $\mu$-open sets. The condition under which both are same are also established here. Some properties of such sets have been discussed. Some closure as operators are also defined and their properties are discussed. The relation between similar types of closure operators on the GTS $(X, \mu)$ has been established. The condition under which the newly defined closure like operator is a Kuratowski closure operator is given. We have also defined a generalized type of closed sets termed as $\gamma_{\mu}$-generalized closed set with the help of this newly defined closure operator and discussed some basic properties of such sets. As an application, we have introduced some weak separation axioms and discussed some of their properties. Finally, we have shown some preservation theorems of such generalized concepts.
\end{abstract}

Keywords: operation, $\mu$-open set, $\gamma_{\mu}$-open set, $\gamma_{\mu} g$-closed set.

\section{Introduction}

In 1979, Kasahara [1] introduced the notion of an operation on a topological space and introduced the concept of an $\alpha$-closed graph of a function. After then Janković defined [2] the concept of $\alpha$-closed sets and investigated some properties of functions with $\alpha$-closed graphs. In 1991 Ogata [3] introduced the notion of $\gamma$-open sets to investigate some new separation axioms of a topological space. Recently, Krishnan et al. [4] and Van An et al. [5] investigated the notion of operations on the family of all semi-open sets and pre-open sets.

In this paper our aim is to study an operation based on open like sets, where the operation is defined on a collection of generalized open sets instead of a topology. The family of open sets plays an important role in topology. For this, different open like sets or weakly open sets have been introduced by mathematicians to study different weak forms of continuous functions and covering properties of topological spaces. But the most common properties of these open like sets or weakly open sets are that they are closed under arbitrary union and contain the empty set. Observing these, Császár introduced the concept of generalized open sets. We now recall some notions defined in [6]. Let $X$ be a non-empty set. A subcollection $\mu \subseteq \mathcal{P}(X)$ (where $\mathcal{P}(X)$ denotes the power set of $X$ ) is called a generalized topology [6], (briefly, GT) if $\varnothing \in \mu$ and any union of elements of $\mu$ belongs to $\mu$. A set $X$ with a GT $\mu$ on the set $X$ is called a generalized topological space (briefly, GTS) and is denoted by $(X, \mu)$. If for a GTS $(X, \mu) X \in \mu$, then $(X, \mu)$ is known as a strong GTS. The elements of $\mu$ are called $\mu$-open sets and $\mu$-closed sets are their complements. The $\mu$-closure of a set $A \subseteq X$ is denoted by $c_{\mu}(A)$ and defined as the smallest $\mu$-closed set containing $A$ which is equivalent to the intersection of all $\mu$-closed sets containing $A$. It is also known from $[7,8]$ that for a $\operatorname{GTS}(X, \mu), A \subseteq X$ and $x \in X, x \in c_{\mu}(A)$ if and only if $U \cap A \neq \emptyset$ for every $U \in \mu$ containing $x$. We use the symbol $i_{\mu}(A)$ to mean the $\mu$-interior of $A$ and it is defined as the union of all $\mu$-open sets contained in $A$ i.e., the largest $\mu$-open set contained in $A$ (see [6, 7]). We observe that $x \in i_{\mu}(A)$ if and only if there exists some $\mu$-open set $U$ containing $x$ such that $U \subseteq A$ and $A \subseteq X$ is $\mu$-open (resp. $\mu$-closed) if and only if $A=i_{\mu}(A)$ (resp. $A=c_{\mu}(A)$ ). It is well known that $i_{\mu}$ and $c_{\mu}$ both are monotonic and idempotent. For any subset $A$ of a $\operatorname{GTS}(X, \mu), i_{\mu}(X \backslash A)=X \backslash c_{\mu}(A)$ holds.

Császár continued to try to find a more general structure from general topology, generalized topology, and minimal structure. In 2010, he introduced the notion of weak structures [9] and proved that it can replace the

\footnotetext{
${ }^{*}$ Corresponding author.

E-mail: bishwambhar_roy@yahoo.co.in
} 
already defined structures in some cases. A sub-collection $w \subseteq \mathcal{P}(X)$ is said to be a weak structure on $X$ if and only if it contains the empty set. Its properties have been investigated intensively in [10-13]. In Section 2 we have introduced the concept of a type of generalized open sets termed as $\gamma_{\mu}$-open sets, the class of which is smaller than that of generalized open sets, by an operator defined on a GT. We have then studied some properties of such sets in detail. In section 3 we have defined a new type of generalized closed sets and studied some separation properties with the help of the idea developed in Section 2.

\section{$\gamma_{\mu}$-open sets and operations}

Definition 2.1. [14] Let $(X, \mu)$ be a GTS. An operation $\gamma_{\mu}$ on a generalized topology $\mu$ is a mapping from $\mu$ to $\mathcal{P}(X)$ (where $\mathcal{P}(X)$ is the power set of $X$ ) with $G \subseteq \gamma_{\mu}(G)$ for each $G \in \mu$. This operation is denoted by $\gamma_{\mu}: \mu \rightarrow \mathcal{P}(X)$. Note that $\gamma_{\mu}(A)$ and $A^{\gamma_{\mu}}$ are two different notation for the same set.

Definition 2.2. [14] Let $(X, \mu)$ be a GTS and $\gamma_{\mu}$ an operation on $\mu$. A subset $G$ of a GTS $(X, \mu)$ is called $\gamma_{\mu}$-open if for each point $x$ of $G$, there exists a $\mu$-open set $U$ containing $x$ such that $\gamma_{\mu}(U) \subseteq G$.

A subset of a $\operatorname{GTS}(X, \mu)$ is called $\gamma_{\mu}$-closed if its complement is $\gamma_{\mu}$-open in $(X, \mu)$. We shall use the symbol $\gamma_{\mu}$ to mean the collection of all $\gamma_{\mu}$-open sets of the GTS $(X, \mu)$.

Remark 2.3. (a) We observe that every $\gamma_{\mu}$-open set is a $\mu$-open set i.e., $\gamma_{\mu} \subseteq \mu$. Let $G \in \gamma_{\mu}$. If $G=\varnothing$ then $G \in \mu$. If $G \neq \varnothing$, let $x \in G$. Then there exists a $\mu$-open set $U$ containing $x$ such that $\gamma_{\mu}(U) \subseteq G$. Thus for each $x \in G$ there exists a $\mu$-open set $U$ containing $x$ such that $x \in U \subseteq G$. Thus $x$ is a $\mu$-interior point of $G$ i.e., $x \in i_{\mu}(G)$ i.e., $G \subseteq i_{\mu}(G)$ proving $G$ to be a $\mu$-open set.

(b) We note that $\gamma_{\mu}$ is a GT on $X$ i.e., $\varnothing \in \gamma_{\mu}$ and arbitrary unions of $\gamma_{\mu}$-open sets are also $\gamma_{\mu}$-open. For let $\left\{G_{\alpha}: \alpha \in I\right\}$ be a family of $\gamma_{\mu}$-open subsets of $X$. We shall show that $\cup\left\{G_{\alpha}: \alpha \in I\right\}$ is also a $\gamma_{\mu}$-open set. In fact, let $x \in \cup\left\{G_{\alpha}: \alpha \in I\right\}$. Then $x \in G_{\alpha_{0}}$ for some $\alpha_{0} \in I$. Thus by $\gamma_{\mu}$-openness of $G_{\alpha_{0}}$, there exists a $\mu$-open set $U$ containing $x$ such that $\gamma_{\mu}(U) \subseteq G_{\alpha_{0}} \subseteq \cup\left\{G_{\alpha}: \alpha \in I\right\}$.

Example 2.4. (a) Let $X=\{1,2,3\}$ and $\mu=\{\varnothing,\{1,2\},\{1,3\}, X\}$. Then $\mu$ is a GT on $X$. Consider the mapping $\gamma_{\mu}: \mu \rightarrow \mathcal{P}(X)$ defined by $\gamma_{\mu}(A)=c_{\mu}(A)$ for each subset $A$ of $X$. It can be easily checked that $\{1,2\}$ is a $\mu$-open set but not a $\gamma_{\mu}$-open set.

(b) Let $X=\{1,2,3\}$ and $\mu=\{\varnothing,\{1\},\{1,2\},\{2,3\}, X\}$. Then $(X, \mu)$ is a GTS. Now $\gamma_{\mu}: \mu \rightarrow \mathcal{P}(X)$ defined by

$$
\gamma_{\mu}(A)=\left\{\begin{array}{c}
A, \text { if } 1 \in A \\
\{2,3\}, \text { otherwise }
\end{array}\right.
$$

is an operation. It can be easily checked that $\{1,2\}$ and $\{2,3\}$ are two $\gamma_{\mu}$-open sets but their intersection $\{2\}$ is not so.

Definition 2.5. A GTS $(X, \mu)$ is said to be a $\gamma_{\mu}$-regular space if for each point $x$ of $X$ and each $\mu$-open set $V$ containing $x$, there exists a $\mu$-open set $U$ containing $x$ such that $\gamma_{\mu}(U) \subseteq V$.

Theorem 2.6. Let $(X, \mu)$ be a GTS and $\gamma_{\mu}: \mu \rightarrow \mathcal{P}(X)$ be an operation on a GTS $X$. Then $(X, \mu)$ is a $\gamma_{\mu}$-regular space if and only if $\mu=\gamma_{\mu}$.

Proof. Let $(X, \mu)$ be a $\gamma_{\mu}$-regular space. In view of Remark 2.3 it is sufficient to show that $\mu \subseteq \gamma_{\mu}$. Let $G$ be a $\mu$-open set of $X$. If $G=\varnothing$, then $G \in \gamma_{\mu}$. Thus we may assume that $G \neq \varnothing$. Since $(X, \mu)$ is $\gamma_{\mu}$-regular, then $G$ is a $\gamma_{\mu}$-open set. Therefore, we have $\mu \subseteq \gamma_{\mu}$.

Conversely, let $x \in X$ and $V$ be a $\mu$-open set containing $x$. Then $V$ is a $\gamma_{\mu}$-open set containing $x\left(\right.$ as $\left.\mu=\gamma_{\mu}\right)$. Thus by definition of $\gamma_{\mu}$-open sets, there exists a $\mu$-open set $U$ containing $x$ such that $\gamma_{\mu}(U) \subseteq V$. Hence $(X, \mu)$ is a $\gamma_{\mu}$-regular space.

Theorem 2.7. A GTS $(X, \mu)$ is a $\gamma_{\mu}$-regular space if and only if for each point $x \in X$ and every $\mu$-open set $U$ containing $x$, there exists a $\gamma_{\mu}$-open set $W$ containing $x$ such that $W \subseteq U$.

Proof. First let us assume that $(X, \mu)$ be a $\gamma_{\mu}$-regular space. Let $x \in \overline{\bar{X}}$ and $U$ be a $\mu$-open set containing $x$. Then by Definition 2.5, there exists a $\mu$-open set $W$ containing $x$ such that $W \subseteq \gamma_{\mu}(W) \subseteq U$. Thus by Theorem 2.6, $W$ is a $\gamma_{\mu}$-open set. Hence there exists a $\gamma_{\mu}$-open set $W$ such that $x \in W \cong U$.

Conversely, suppose that for each point $x \in X$ and every $\mu$-open set $U$ containing $x$ there exists a $\gamma_{\mu}$-open set $W$ containing $x$ such that $W \subseteq U$. In view of Theorem 2.6 and Remark 2.3(a) it is now sufficient to show that $\mu \subseteq \gamma_{\mu}$. Let $U \in \mu$ and $x \in \bar{U}$. Then by the given condition there exists a $\gamma_{\mu}$-open set $W_{x}$ containing $x$ such that $W_{x} \subseteq U$. Thus $U=\cup\left\{W_{x}: x \in U\right.$ and $W_{x}$ is $\gamma_{\mu}$-open $\}$. Thus by Remark 2.3(b), $U$ is $\gamma_{\mu}$-open.

Definition 2.8. Let $(X, \mu)$ be a GTS. An operation $\gamma_{\mu}: \mu \rightarrow \mathcal{P}(X)$ is said to be regular if for each point $x \in X$ and any two $\mu$-open sets $U$ and $V$ of $X$ containing $x$ there exists a $\mu$-open set $W$ containing $x$ such that $\gamma_{\mu}(W) \subseteq \gamma_{\mu}(U) \cap \gamma_{\mu}(V)$. 
Theorem 2.9. Let $\gamma_{\mu}: \mu \rightarrow \mathcal{P}(X)$ be a regular operation. Then the intersection of two $\gamma_{\mu}$-open sets is also a $\gamma_{\mu}$-open set. Furthermore, $\gamma_{\mu}$ is a topology if $X \in \mu$.

Proof. Let $G$ and $H$ be two $\gamma_{\mu}$-open sets in a GTS $(X, \mu)$. We shall show that $G \cap H$ is also a $\gamma_{\mu}$-open set. If $G \cap H=\varnothing$ then the proof is done. Let $x \in G \cap H$. Then by Definition 2.2, there exist two $\mu$-open sets $U$ and $V$ with $x \in U \cap V$ such that $\gamma_{\mu}(U) \subseteq G$ and $\gamma_{\mu}(V) \subseteq H$. Since $\gamma_{\mu}: \mu \rightarrow \mathcal{P}(X)$ is a regular operation, there exists a $\mu$-open set $W$ containing $x$ such that $\gamma_{\mu}(W) \subseteq \gamma_{\mu}(U) \cap \gamma_{\mu}(V) \subseteq G \cap H$. Thus by Definition $2.2, G \cap H$ is $\gamma_{\mu}$-open.

If $X \in \mu$, then for each $x \in X$, there exists a $\mu$-open set $X$ (as $X \in \mu$ ) containing $x$ such that $X \subseteq \gamma_{\mu}(X) \subseteq X$. Thus $X$ is a $\gamma_{\mu}$-open set. It follows from Remark 2.3(b) that arbitrary union of $\gamma_{\mu}$-open sets is a $\gamma_{\mu}$-open set. Thus $\gamma_{\mu}$ is a topology on $X$.

Example 2.10. (a) Let $X=\{1,2,3\}$ and $\mu=\{\varnothing,\{1\},\{2\},\{1,2\}\}$. Then $\gamma_{\mu}: \mu \rightarrow \mathcal{P}(X)$ defined by $\gamma_{\mu}(A)=c_{\mu}(A)$ is an operation on the GTS $(X, \mu)$ where $\mu$ is not strong. It can be easily checked the $X$ is not a $\gamma_{\mu}$-open set. We note that $\gamma_{\mu}: \mu \rightarrow \mathcal{P}(X)$ is a regular operation.

(b) Let $X=\{1,2,3\}, \mu=\{\varnothing, X,\{2\},\{1,3\},\{2,3\}\}$. Then $\gamma_{\mu}: \mu \rightarrow \mathcal{P}(X)$ defined by

$$
\gamma_{\mu}(A)=\left\{\begin{array}{l}
A \cup\{1\}, \text { if } A \text { is any singleton subset of } X \\
A, \text { otherwise }
\end{array}\right.
$$

is an operation on the GTS $(X, \mu)$. We note that $\gamma_{\mu}$ is not a regular operation. It can be checked easily that $\gamma_{\mu}$ is not a topology on $X$.

We now define the following two types of closure operators : one follows from the GT $\gamma_{\mu}$ on $X$ and the second one is defined in the sense of Jankovič.

Definition 2.11. Let $(X, \mu)$ be a GTS and $\gamma_{\mu}: \mu \rightarrow \mathcal{P}(X)$ be an operation.

(a) It follows from Remark 2.3(b) that $\gamma_{\mu}$ is a GT. Thus the $\gamma_{\mu}$-closure of a set $A$ is denoted by $c_{\gamma_{\mu}}(A)$ and is defined as $c_{\gamma_{\mu}}(A)=\cap\left\{F: F\right.$ is a $\gamma_{\mu}$-closed set and $\left.A \subseteq F\right\}$.

(b) $\gamma_{\mu}^{*}$-closure of $A$ is denoted by $\gamma_{\mu}-c(A)$ and defined by $\gamma_{\mu}-c(A)=\left\{x: A \cap \gamma_{\mu}(U) \neq \varnothing\right.$ for every $\mu$-open set $U$ containing $x\}$.

A subset $A(\subseteq X)$ is called $\gamma_{\mu}^{*}$-closed if $\gamma_{\mu}-c(A)=A$.

Proposition 2.12. Let $(X, \mu)$ be a GTS and $\gamma_{\mu}: \mu \rightarrow \mathcal{P}(X)$ be an operation. For each $x \in X, x \in c_{\gamma_{\mu}}(A)$ if and only if $V \cap A \neq \varnothing$ for any $V \in \gamma_{\mu}$ with $x \in V$.

Proof. The proof follows from the fact that $\gamma_{\mu}$ is a GT on $X$ ( by Remark 2.3(b)) and the fact that for any GT $\mu$ on $X, x \in c_{\mu}(A)[7,8]$ if and only if $U \cap A \neq \varnothing$ for each $\mu$-open set $U$ containing $x$.

Remark 2.13. It can be checked easily that for any subset $A$ of a GTS $(X, \mu), A \subseteq c_{\mu}(A) \subseteq \gamma_{\mu}-c(A) \subseteq c_{\gamma_{\mu}}(A)$.

Definition 2.14. An operation $\gamma_{\mu}: \mu \rightarrow \mathcal{P}(X)$ is said to be $\mu$-open if for each point $x$ of $X$ and for every $\mu$-open set $U$ containing $x$ there exists a $\gamma_{\mu}$-open set $V$ containing $x$ such that $V \cong \gamma_{\mu}(U)$.

The next theorem gives the relation between the three types of closure operators.

Theorem 2.15. Let $(X, \mu)$ be a GTS, $\gamma_{\mu}: \mu \rightarrow \mathcal{P}(X)$ an operation and $A$ a subset of $X$.

(i) The subset $\gamma_{\mu}-c(A)$ is $\mu$-closed in $(X, \mu)$.

(ii) If $(X, \mu)$ is $\gamma_{\mu}$-regular, then $\gamma_{\mu}-c(A)=c_{\mu}(A)$.

(iii) If $\gamma_{\mu}$ is $\mu$-open, then $\gamma_{\mu}-c(A)=c_{\gamma_{\mu}}(A)$ and $\gamma_{\mu}-c\left[\gamma_{\mu}-c(A)\right]=\gamma_{\mu}-c(A)$.

Proof. (i) We shall only show that $c_{\mu}\left[\gamma_{\mu}-c(A)\right] \subseteq \gamma_{\mu}-c(A)$. Let $x \in c_{\mu}\left[\gamma_{\mu}-c(A)\right]$ and $U$ be any $\mu$-open set in $X$ containing $x$. Then $U \cap \gamma_{\mu}-c(A) \neq \varnothing$. Let $y \in U \cap \gamma_{\mu}-c(A)$. Then $y \in U$ and $y \in \gamma_{\mu}-c(A)$. Thus $\gamma_{\mu}(U) \cap A \neq \varnothing$ i.e., $x \in \gamma_{\mu}-c(A)$ (by Definition 2.11).

(ii) In view of Remark 2.13 we need only to show that in a $\gamma_{\mu}$-regular GTS $(X, \mu), \gamma_{\mu}-c(A) \subseteq c_{\mu}(A)$. Let $x \in \gamma_{\mu}-c(A)$ and $G$ be any $\mu$-open set containing $x$. Then there exists a $\mu$-open set $U$ containing $x$ such that $\gamma_{\mu}(U) \subseteq G\left(\right.$ as $(X, \mu)$ is $\gamma_{\mu}$-regular). Since $x \in \gamma_{\mu}-c(A)$ we have $\gamma_{\mu}(U) \cap A \neq \varnothing$ and hence $G \cap A \neq \varnothing$. Thus it follows that $x \in c_{\mu}(A)$.

(iii) Suppose that $x \notin \gamma_{\mu}-c(A)$. Then there exists a $\mu$-open set $U$ containing $x$ such that $\gamma_{\mu}(U) \cap A=\varnothing$. Since $\gamma_{\mu}$ is $\mu$-open, for the $\mu$-open set $U$ containing $x$, there exists a $\gamma_{\mu}$-open set $V$ containing $x$ such that $V \subseteq \gamma_{\mu}(U)$. Hence $V \cap A=\varnothing$. This shows that $x \notin c_{\gamma_{\mu}}(A)$. Thus $c_{\gamma_{\mu}}(A) \subseteq \gamma_{\mu}-c(A)$. Also from Remark 2.13, $\gamma_{\mu}-c(A) \subseteq c_{\gamma_{\mu}}(A)$. Thus we have $\gamma_{\mu}-c(A)=c_{\gamma_{\mu}}(A)$. Hence $\gamma_{\mu}-c\left[\gamma_{\mu}-c(A)\right]=c_{\gamma_{\mu}}\left[c_{\gamma_{\mu}}(A)\right]=c_{\gamma_{\mu}}(A)$ (as $\gamma_{\mu}$ is a GT on $X$ and $c_{\gamma_{\mu}}$ is idempotent $)=\gamma_{\mu}-c(A)$. by

Example 2.16. (a) Let $X=\{1,2,3\}, \mu=\{\varnothing,\{1\},\{3\},\{1,2\},\{1,3\},\{2,3\}, X\}$. Then $\gamma_{\mu}: \mu \rightarrow \mathcal{P}(X)$ defined

$$
\gamma_{\mu}(A)=\left\{\begin{array}{l}
A \cup\{3\}, \text { if } A \neq\{1\} \\
A, \text { otherwise }
\end{array}\right.
$$


is an operation. It can be easily checked that $c_{\mu}(\{3\})=\{3\} \neq \gamma_{\mu}-c(\{3\})=\{2,3\}$ and thus from Theorem 2.15 it follows that $(X, \mu)$ is not $\gamma_{\mu}$-regular.

(b) Let $X=\{1,2,3,4\}, \mu=\{\varnothing,\{1,2\},\{2,3\},\{1,4\},\{1,2,3\},\{1,2,4\},\{2,3,4\}, X\}$. Then $\gamma_{\mu}: \mu \rightarrow \mathcal{P}(X)$ defined by

$$
\gamma_{\mu}(A)=\left\{\begin{array}{l}
A, \text { if } 1 \in A \\
A \cup\{1\}, \text { if } 1 \notin A
\end{array}\right.
$$

is an operation. It can be checked that $\gamma_{\mu}-c(\{2\})=\{2,3,4\}$ but $\gamma_{\mu}-c\left[\gamma_{\mu}-c(\{2\})\right]=X \neq \gamma_{\mu}-c(\{2\})$. Thus it follows from Theorem 2.15 that $\gamma_{\mu}$ is not $\mu$-open.

Theorem 2.17. Let $\mu$ be a GT on a set $X$ and $\gamma_{\mu}: \mu \rightarrow \mathcal{P}(X)$ be an operation. For any subset $A$ of $X$ the followings are equivalent :

(i) $A$ is $\gamma_{\mu}$-open in $(X, \mu)$.

(ii) $X \backslash A$ is $\gamma_{\mu}^{*}$-closed in $(X, \mu)$.

(iii) $c_{\gamma_{\mu}}(X \backslash A)=X \backslash A$ holds.

(iv) $X \backslash A$ is $\gamma_{\mu}$-closed in $(X, \mu)$.

Proof. (i) $\Rightarrow$ (ii): Let $x \notin X \backslash A$. Then $x \in A$. Thus there exists a $\mu$-open set $U$ containing $x$ such that $\gamma_{\mu}(U) \subseteq A$ i.e., $\gamma_{\mu}(U) \cap(X \backslash A)=\varnothing$. This shows that $x \notin \gamma_{\mu}-c(X \backslash A)$. Thus it follows that $\gamma_{\mu}-c(X \backslash A) \subseteq X \backslash A$.

(ii) $\Rightarrow$ (iii): We have to show that $c_{\gamma_{\mu}}(X \backslash A) \subseteq X \backslash A$. Let $x \notin X \backslash A$. It then follows from (ii) that there exists a $\mu$-open set $U$ containing $x$ such that $\gamma_{\mu}(U) \cap(X \backslash A)=\varnothing$. Then $A$ is a $\gamma_{\mu}$-open set containing $x$. Therefore $A \cap(X \backslash A)=\varnothing$ and hence $x \notin c_{\gamma_{\mu}}(X \backslash A)$.

(iii) $\Rightarrow$ (iv): We shall show that $A$ is $\gamma_{\mu}$-open. Let $x \in A$. Then by Proposition 2.12 and (iii), there exists a $\gamma_{\mu}$-open set $U$ containing $x$ such that $U \cap(X \backslash A)=\varnothing$. Since $U$ is $\gamma_{\mu}$-open and $x \in U$, there exists a $\mu$-open set $V$ containing $x$ such that $\gamma_{\mu}(V) \subseteq U$. Thus we have $x \in \gamma_{\mu}(V) \subseteq U \subseteq A$ and hence $A$ is $\gamma_{\mu}$-open.

(iv) $\Rightarrow$ (i) : The proof follows from the definition.

Theorem 2.18. Let $(X, \mu)$ be a GTS and $\gamma_{\mu}: \mu \rightarrow \mathcal{P}(X)$ be an operation. If $\gamma_{\mu}$ is regular, then $\gamma_{\mu}-c(A \cup B)=\gamma_{\mu}-c(A) \cup \gamma_{\mu}-c(B)$ for any two subsets $A$ and $B$ of $X$.

Proof. Let $x \notin \gamma_{\mu}-c(A) \cup \gamma_{\mu}-c(B)$. Then $x \notin \gamma_{\mu}-c(A)$ and $x \notin \gamma_{\mu}-c(B)$. Hence there exist two $\mu$-open sets $U$ and $V$ containing $x$ such that $\gamma_{\mu}(U) \cap A=\gamma_{\mu}(V) \cap B=\varnothing$. Since $\gamma_{\mu}$ is regular, there exists a $\mu$-open set $W$ containing $x$ such that $\gamma_{\mu}(W) \subseteq \gamma_{\mu}(U) \cap \gamma_{\mu}(V)$. Therefore, we have $(A \cup B) \cap \gamma_{\mu}(W) \subseteq(A \cup B) \cap\left[\gamma_{\mu}(U) \cap \gamma_{\mu}(V)\right] \subseteq$ $\subseteq\left[A \cap \gamma_{\mu}(U)\right] \cup\left[B \cap \gamma_{\mu}(V)\right]=\varnothing$. Hence $x \notin \gamma_{\mu}-c(A \cup B)$. Therefore, we obtain $\gamma_{\mu}-c(A \cup B) \subseteq \gamma_{\mu}-c(A) \cup \gamma_{\mu}-c(B)$.

Corollary 2.19. Let $\mu$ be a GT on a set $X$ and $\gamma_{\mu}: \mu \rightarrow \mathcal{P}(X)$ be an operation. If $\gamma_{\mu}$ is regular and $\mu$-open, then the mapping defined by $\psi(A)=\gamma_{\mu}-c(A)$ for $A \cong X$ is a Kuratowski closure operator.

Proof. This follows from Theorem 2.15, Theorem 2.18 and Definition 2.11.

$$
\gamma_{\mu} \text {-generalized closed sets and } \gamma_{\mu}-T_{i} \text { spaces }(i=0,1 / 2,1,2)
$$

Definition 3.1. Let $\gamma_{\mu}: \mu \rightarrow \mathcal{P}(X)$ be an operation. A subset $A$ of a GTS $(X, \mu)$ is said to be $\gamma_{\mu}$-generalized closed (briefly $\gamma_{\mu} g$-closed) if $\gamma_{\mu}-c(A) \subseteq U$ whenever $A \subseteq U$ and $U$ is $\gamma_{\mu}$-open.

The complement of a $\gamma_{\mu} g$-closed set is called a $\gamma_{\mu} g$-open set.

We observe that every $\gamma_{\mu}^{*}$-closed set is $\gamma_{\mu} g$-closed. The converse is false as shown in the next example. by

Example 3.2. Consider $X=\{1,2,3\}, \mu=\{\varnothing,\{1\},\{3\},\{1,2\},\{1,3\},\{2,3\}\}$. Then $\gamma_{\mu}: \mu \rightarrow \mathcal{P}(X)$ defined

$$
\gamma_{\mu}(A)=\left\{\begin{array}{l}
A \cup\{2\}, \text { if } A \neq\{1\} \\
A, \text { otherwise }
\end{array}\right.
$$

is an operation. It can be checked easily that $\{1,3\}$ is $\gamma_{\mu} g$-closed but not $\gamma_{\mu}$-closed.

The following theorem gives the characterizations of $\gamma_{\mu} g$-closed sets.

Theorem 3.3. Let $\gamma_{\mu}: \mu \rightarrow \mathcal{P}(X)$ be an operation. Then for any $A \subseteq X$, the following are equivalent:

(i) $A$ is $\gamma_{\mu} g$-closed.

(ii) For each $x \in \gamma_{\mu}-c(A), c_{\gamma_{\mu}}(\{x\}) \cap A \neq \varnothing$.

(iii) $\gamma_{\mu}-c(A) \subseteq \operatorname{Ker}_{\gamma_{\mu}}(A)$ (where $\operatorname{Ker}_{\gamma_{\mu}}(A)=\cap\left\{V: A \subseteq V\right.$ and $V$ is $\gamma_{\mu}$-open $\}$ see [15] for detail).

Proof. (i) $\Rightarrow$ (ii) : Suppose that $A$ be a $\gamma_{\mu} g$-closed subset and also suppose that there exists a point $x \in \gamma_{\mu}-c(A)$ for which $c_{\gamma_{\mu}}(\{x\}) \cap A=\varnothing$. Then $c_{\gamma_{\mu}}(\{x\})$ is $\gamma_{\mu}$-closed (by Remark 2.3(b) and Definition 2.11(a)). Put $U=X \backslash c_{\gamma_{\mu}}(\{x\})$. Then $A \subseteq U$ and $x \notin U$ with $U$ a $\gamma_{\mu}$-open set in $(X, \mu)$. Since $A$ is $\gamma_{\mu} g$-closed, $\gamma_{\mu}-c(A) \subseteq U$. Thus $x \notin \gamma_{\mu}-c(A)$ which is a contradiction. 
(ii) $\Rightarrow$ (iii) : Let $x \in \gamma_{\mu}-c(A)$. We have only to show that $x \in \operatorname{Ker}_{\gamma_{\mu}}(A)$. By (ii) there exists a point $z \in A$ such that $z \in c_{\gamma_{\mu}}(\{x\})$. Let $U$ be any $\gamma_{\mu}$-open subset of $X$ such that $A \subseteq U$. Since $z \in U$ and $z \in c_{\gamma_{\mu}}(\{x\})$, by Proposition 2.12 we have $U \cap\{x\} \neq \varnothing$ i.e., $x \in U$. Thus $x \in \operatorname{Ker}_{\gamma_{\mu}}(A)$.

(iii) $\Rightarrow$ (i) : Let $A \subseteq U$, where $U$ be any $\gamma_{\mu}$-open set. Let $x \in \gamma_{\mu}-c(A)$. It then follows from (iii) that $x \in \operatorname{Ker}_{\gamma_{\mu}}(A)$. Thus $x \in U$ i.e., $\gamma_{\mu}-c(A) \subseteq U$.

Theorem 3.4. Let $\gamma_{\mu}: \mu \rightarrow \mathcal{P}(X)$ be an operation, where $(X, \mu)$ is a GTS. For each point $x$ of $X,\{x\}$ is a $\gamma_{\mu}$-closed set or $X \backslash\{x\}$ is a $\gamma_{\mu} g$-closed set in $(X, \mu)$.

Proof. Let $\{x\}$ be not a $\gamma_{\mu}$-closed set. Then the complement $X \backslash\{x\}$ is not a $\gamma_{\mu}$-open set. Let $U$ be any $\gamma_{\mu}$-open set with $X \backslash\{x\} \subseteq U$. Then $U$ must be equal to $X$. Thus $\gamma_{\mu}-c(X \backslash\{x\}) \subseteq U$. Thus $X \backslash\{x\}$ is $\gamma_{\mu} g$-closed.

Proposition 3.5. Let $\gamma_{\mu}: \mu \rightarrow \mathcal{P}(X)$ be an operation and $A$ be a subset of a GTS $(X, \mu)$. If $A$ is $\gamma_{\mu} g$-closed, then $\gamma_{\mu}-c(A) \backslash A$ does not contain any non-empty $\gamma_{\mu}$-closed set. If the operation $\gamma_{\mu}: \mu \rightarrow \mathcal{P}(X)$ is $\mu$-open, then the converse part is also true.

Proof. If possible, let $F$ be any $\gamma_{\mu}$-closed set contained in $\gamma_{\mu}-c(A) \backslash A$. Then $A \subseteq X \backslash F$ where $X \backslash F$ is a $\gamma_{\mu}$-open set. Thus $\gamma_{\mu}-c(A) \subseteq X \backslash F$ (as $A$ is $\gamma_{\mu} g$-closed). Thus $F \subseteq X \backslash \gamma_{\mu}-c(A)$. Also $F \subseteq \gamma_{\mu}-c(A)$. Thus $F \stackrel{\text { ㅇ․ }}{=} \gamma_{\mu}-c(A) \cap\left(X \backslash \gamma_{\mu}-c(A)\right)=\varnothing$, which is a contradiction. Thus $F=\varnothing$.

Conversely, let $A \subseteq U$ where $U$ be any $\gamma_{\mu}$-open set. Since the operation $\gamma_{\mu}$ is $\mu$-open, by Theorem 2.15 $\gamma_{\mu}-c(A)$ is $\gamma_{\mu}$-closed. Thus $\gamma_{\mu}-c(A) \cap(X \backslash U)=F$ (say) is a $\gamma_{\mu}$-closed set (by Remark 2.3(b) and Definition 2.11(a)). Since $X \backslash U \subseteq X \backslash A, F \leqq \gamma_{\mu}-c(A) \backslash A$. Thus by the assumption it follows that $F=\varnothing$ and hence we have $\gamma_{\mu}-c(A) \subseteq U$.

Definition 3.6. Let $\gamma_{\mu}: \mu \rightarrow \mathcal{P}(X)$ be an operation, where $\mu$ is a GT on $X$. Then $(X, \mu)$ is said to be a $\gamma_{\mu}-T_{1 / 2}$ space if every $\gamma_{\mu} g$-closed set is a $\gamma_{\mu}$-closed set.

The next theorem characterizes a $\gamma_{\mu}-T_{1 / 2}$ GTS.

Theorem 3.7. Let $\gamma_{\mu}: \mu \rightarrow \mathcal{P}(X)$ be an operation, where $\mu$ is a GT on $X$. Then $(X, \mu)$ is $\gamma_{\mu}-T_{1 / 2}$ if and only if for each $x \in X,\{x\}$ is either $\gamma_{\mu}$-open or $\gamma_{\mu}$-closed.

Proof. Suppose that that $(X, \mu)$ is $\gamma_{\mu}-T_{1 / 2}$ and $\{x\}$ is not $\gamma_{\mu}$-closed. Then by Theorem 3.4, $X \backslash\{x\}$ is $\gamma_{\mu} g$-closed. Since $(X, \mu)$ is $\gamma_{\mu}-T_{1 / 2}, X \backslash\{x\}$ is $\gamma_{\mu}$-closed. Thus $\{x\}$ is $\gamma_{\mu}$-open.

Conversely, let $F$ be a $\gamma_{\mu} g$-closed set in $(X, \mu)$. By Theorem 2.17, it is sufficient to show that $\gamma_{\mu}-c(F) \subseteq F$. If possible, let there exist a point $x \in \gamma_{\mu}-c(F) \backslash F$. Then by the given condition $\{x\}$ is either $\gamma_{\mu}$-open or $\gamma_{\mu}$-closed. Case $-1:\{x\}$ is $\gamma_{\mu}$-closed : For this case we have a $\gamma_{\mu}$-closed set $\{x\}$ such that $\{x\} \subseteq \gamma_{\mu}-c(F) \backslash F$. This is contrary to Proposition 3.5 .

Case $-2:\{x\}$ is $\gamma_{\mu}$-open : Then by Remark 2.13, $x \in c_{\gamma_{\mu}}(F)$. Thus $\{x\} \cap F \neq \varnothing$. This is a contradiction. Thus we have $\gamma_{\mu}-c(F) \subseteq F$.

Definition 3.8. Let $\gamma_{\mu}: \mu \rightarrow \mathcal{P}(X)$ be an operation, where $\mu$ is a GT on $X$. Then $(X, \mu)$ is said to be (a) $\gamma_{\mu}-T_{0}$ if for each pair of distinct points $x, y \in X$, there exists a $\mu$-open set $G$ such that either $x \in G$ and $y \notin \gamma_{\mu}(G)$, or $y \in G$ and $x \notin \gamma_{\mu}(G)$.

(b) $\gamma_{\mu}-T_{1}$ if for each pair of distinct points $x, y \in X$, there exist $\mu$-open sets $G$ and $H$ containing $x$ and $y$, respectively, such that either $y \notin \gamma_{\mu}(G)$ and $x \notin \gamma_{\mu}(H)$.

(c) $\gamma_{\mu}-T_{2}$ if for each pair of distinct points $x, y \stackrel{\mu}{\in} X$, there exist $\mu$-open sets $G$ and $H$ containing $x$ and $y$, respectively, such that $\gamma_{\mu}(G) \cap \gamma_{\mu}(H)=\varnothing$.

A $\gamma_{\mu}-T_{1}$ GTS is characterized by the following theorem.

Theorem 3.9. Let $\gamma_{\mu}: \mu \rightarrow \mathcal{P}(X)$ be an operation, where $\mu$ is a GT on $X$. Then the following are equivalent:

(i) $(X, \mu)$ is $\gamma_{\mu}-T_{1}$.

(ii) For each $x \in X,\{x\}$ is a $\gamma_{\mu}^{*}$-closed set.

(iii) For each pair of distinct points $x, y \in X$ there exist $\gamma_{\mu}$-open sets $U$ and $V$ containing $x$ and $y$, respectively, such that either $y \notin U$ and $x \notin V$.

Proof. (i) $\Rightarrow$ (ii) : Let $x \in X$. We shall show that $\{x\}$ is $\gamma_{\mu}^{*}$-closed. Let $y \notin\{x\}$. Then by (i) there exists a $\mu$-open set $U_{y}$ such that $y \in U_{y}, x \notin \gamma_{\mu}\left(U_{y}\right)$. Thus $\gamma_{\mu}\left(U_{y}\right) \cap\{x\}^{\mu}=\varnothing$. Thus $y \notin \gamma_{\mu}-c(\{x\})$. Thus $\{x\}$ is $\gamma_{\mu}^{*}$-closed.

(ii) $\Rightarrow$ (iii) Let $x$ and $y$ be two points of $X$ with $x \neq y$. Then by (ii) $\{x\}$ and $\{y\}$ are two $\gamma_{\mu}$-closed sets and hence by Theorem 2.17, X\\{y\} and $X \backslash\{x\}$ are two $\gamma_{\mu}$-open sets containing $x$ and $y$, respectively, such that $x \in(X \backslash\{y\})$ and $y \in(X \backslash\{x\})$.

(iii) $\Rightarrow$ (i) : Obvious.

Let $\gamma_{\mu}: \mu \rightarrow \mathcal{P}(X)$ be an operation, where $\mu$ is a GT on $X$. Then it follows from Definitions 3.6 and 3.8 that $\gamma_{\mu}-T_{2} \Rightarrow \gamma_{\mu}-T_{1} \Rightarrow \gamma_{\mu}-T_{1 / 2} \Rightarrow \gamma_{\mu}-T_{0}$. None of the implications are reversible as shown in the next example. 
Example 3.10. (a) Let $X=\{1,2,3\}$ and $\mu=\mathcal{P}(X)$. Then $\mu$ is a GT on $X$. Then $\gamma_{\mu}: \mu \rightarrow \mathcal{P}(X)$ defined by

$$
\gamma_{\mu}(A)=\left\{\begin{array}{l}
A \cup\{2\}, \text { if } A=\{1\} \\
A \cup\{3\}, \text { if } A=\{2\} \\
A \cup\{1\}, \text { if } A=\{3\} \\
A, \text { otherwise }
\end{array}\right.
$$

is an operation. It can be checked that $(X, \mu)$ is $\gamma_{\mu}-T_{1}$ but not a $\gamma_{\mu}-T_{2}$ space.

(b) Let $X=\{1,2,3\}$ and $\mu=\mathcal{P}(X)$. Then $\mu$ is a GT on $X$. Then $\gamma_{\mu}: \mu \rightarrow \mathcal{P}(X)$ defined by

$$
\gamma_{\mu}(A)=\left\{\begin{array}{l}
A \cup\{3\}, \text { if } A \neq\{1\} \\
A, \text { otherwise }
\end{array}\right.
$$

is an operation. It can be checked that $(X, \mu)$ is $\gamma_{\mu}-T_{1 / 2}$ but not a $\gamma_{\mu}-T_{1}$ space.

(c) Let $X=\{1,2,3\}$ and $\mu=\{\varnothing,\{1\},\{1,2\},\{1,3\}, X\}$. Then $\mu$ is a GT on $X$. Then $\gamma_{\mu}: \mu \rightarrow \mathcal{P}(X)$ defined by

$$
\gamma_{\mu}(A)=\left\{\begin{array}{c}
A, \text { if } A \neq\{1\} \\
\{1,2\}, \text { otherwise }
\end{array}\right.
$$

is an operation. It can be checked that $(X, \mu)$ is $\gamma_{\mu}-T_{0}$ but not a $\gamma_{\mu}-T_{1 / 2}$ space.

Throughout the rest of the paper $(X, \mu)$ and $(Y, \lambda)$ will denote GTS's and $\gamma_{\mu}: \mu \rightarrow \mathcal{P}(X)$ and $\beta_{\lambda}: \lambda \rightarrow \mathcal{P}(Y)$ will denote two operations on $\mu$ and $\lambda$ respectively.

Definition 3.11. A function $f:(X, \mu) \rightarrow(Y, \lambda)$ is said to be $(\gamma, \beta)$-continuous if for each $x \in X$ and each $\lambda$-open set $V$ with $f(x) \in V$ there exists a $\mu$-open set $U$ containing $x$ such that $f\left(\gamma_{\mu}(U)\right) \subseteq \beta_{\lambda}(V)$.

Theorem 3.12. A $(\gamma, \beta)$-continuous mapping $f:(X, \mu) \rightarrow(Y, \lambda)$ satisfies the following properties:

(i) $f\left(\gamma_{\mu}-c(A)\right) \subseteq \beta_{\lambda}-c(f(A))$ for every subset $A$ of $X$.

(ii) $f^{-1}(W)$ is $\gamma_{\mu}$-open for every $\beta_{\lambda}$-open set $W$ of $Y$, i.e., the inverse image of any $\beta_{\lambda}$-closed set of $(Y, \beta)$ is $\gamma_{\mu}$-closed in $(X, \mu)$.

Proof. (i) Let $y$ be a point of $f\left(\gamma_{\mu}-c(A)\right)$ and $V$ be any $\lambda$-open set containing $y$. Then there exists a point $x$ in $X$ such that $f(x)=y$ and $x \in \gamma_{\mu}-c(A)$. Thus by $(\gamma, \beta)$-continuity of $f$ there exists a $\mu$-open set $U$ containing $x$ such that $f\left(\gamma_{\mu}(U)\right) \subseteq \beta_{\lambda}(V)$. As $x \in \gamma_{\mu}-c(A)$, we have $\gamma_{\mu}(U) \cap A \neq \varnothing$, and hence $\varnothing \neq f\left(\gamma_{\mu}(U) \cap A\right) \subseteq$ $\subseteq f\left(\gamma_{\mu}(U)\right) \cap f(A) \subseteq \beta_{\lambda}(V) \cap f(A)$. This shows that $y \in \beta_{\lambda}-c(f(A))$.

(ii) Let $W$ be a $\beta_{\lambda}$-open set in $(Y, \lambda)$ and $x$ any point of $f^{-1}(W)$. We have to show that $f^{-1}(W)$ is $\gamma_{\mu}$-open. There exists a $\beta$-open set $V$ containing $f(x)$ such that $\beta_{\lambda}(V) \subseteq W$. Thus by $(\gamma, \beta)$-continuity of $f$, there exists a $\mu$-open set $U$ containing $x$ such that $f\left(\gamma_{\mu}(U)\right) \subseteq \beta_{\lambda}(V)$. Thus $\gamma_{\mu}(U) \subseteq f^{-1}\left(\beta_{\lambda}(V)\right) \subseteq f^{-1}(W)$. Thus $f^{-1}(W)$ is $\gamma_{\mu}$-open.

Definition 3.13. A function $f:(X, \mu) \rightarrow(Y, \lambda)$ is said to be $(\gamma, \beta)$-closed if for any $\gamma_{\mu}$-closed set $A$ of $X$, $f(A)$ is a $\beta_{\lambda}$-closed set in $Y$.

Let $i d_{\mu}: \mu \rightarrow \mathcal{P}(X)$ be the identity operation, where $(X, \mu)$ is a GTS. We note that $i d_{\mu}$-open sets and $\mu$-open sets are identical.

Proposition 3.14. Let $f:(X, \mu) \rightarrow(Y, \lambda)$ be a $(\gamma, \beta)$-continuous function and $f$ be a $(i d, \beta)$-closed mapping. The following properties hold:

(i) For each $\gamma_{\mu} g$-closed set $A$ of $X, f(A)$ is $\beta_{\lambda} g$-closed in $Y$.

(ii) For each $\beta_{\lambda} g$-closed set $B$ of $Y, f^{-1}(B)$ is $\gamma_{\mu} g$-closed.

Proof. (i) Let $V$ be any $\beta_{\lambda}$-open set of $(Y, \lambda)$ with $f(A) \subseteq V$. Then by Theorem 3.12 (ii), $f^{-1}(V)$ is a $\gamma_{\mu}$-open set. Now as $A$ is a $\gamma_{\mu} g$-closed set and $A \subseteq f^{-1}(V)$, we have $\gamma_{\mu}-c(A) \subseteq f^{-1}(V)$, and thus $f\left(\gamma_{\mu}-c(A)\right) \subseteq V$. From the assumption and Theorem 2.15(i) it follows that, $f\left(\gamma_{\mu}-c(A)\right)$ is $\beta_{\lambda}$-closed. Thus by Remark 2.13, we have $\beta_{\lambda}-c(f(A)) \subseteq c_{\beta_{\lambda}}\left(\left(f\left(\gamma_{\mu}-c(A)\right)\right)\right)=f\left(\gamma_{\mu}-c(A)\right) \subseteq V$. This shows that $f(A)$ is $\beta_{\lambda} g$-closed in $Y$.

(ii) Let $U$ be any $\gamma_{\mu}$-open set of $(X, \mu)$ such that $f^{-1}(B)$ is contained in $U$. Let $F=\gamma_{\mu}-c\left(f^{-1}(B)\right) \cap(X \backslash U)$. Then $F$ is $\mu$-closed in $(X, \mu)$ (by Theorem 2.15(i) and Remark 2.3(a)). Since $f$ is a $(i d, \beta)$-closed function, $f(F)$ is a $\beta_{\lambda}$-closed set in $(Y, \lambda)$. Then by Proposition 3.5 and the relation $f(F) \subseteq \beta_{\lambda}-c(B) \backslash B$, it follows that $f(F)=\varnothing$ and thus $F=\varnothing$. Thus $\gamma_{\mu}-c\left(f^{-1}(B)\right) \subseteq U$ i.e., $f^{-1}(B)$ is $\gamma_{\mu} g$-closed.

Theorem 3.15. Let $f:(X, \mu) \rightarrow(Y, \lambda)$ be a $(\gamma, \beta)$-continuous and $(i d, \beta)$-closed function.

(i) If $f$ is an injective function and $(Y, \lambda)$ is a $\beta_{\lambda}-T_{1 / 2}$ space, then $(X, \mu)$ is a $\gamma_{\mu}-T_{1 / 2}$ space.

(ii) If $f$ is a surjective function and $(X, \mu)$ is a $\gamma_{\mu}-T_{1 / 2}$ space, then $(Y, \lambda)$ is a $\beta_{\lambda}-T_{1 / 2}$ space.

(iii) If $f$ is bijective, then $(X, \mu)$ is a $\gamma_{\mu}-T_{1 / 2}$ space if and only if $(Y, \lambda)$ is a $\beta_{\lambda}-T_{1 / 2}$ space. 
Proof. (i) We need only to show that every $\gamma_{\mu} g$-closed set is $\gamma_{\mu}$-closed. Let $A$ be a $\gamma_{\mu} g$-closed set of $(X, \mu)$. It then follows from Proposition 3.14(i) that $f(A)$ is $\beta_{\lambda} g$-closed and thus $f(A)$ is $\beta_{\lambda}$-closed (as $(Y, \lambda)$ is $\left.\beta_{\lambda}-T_{1 / 2}\right)$. Now by Theorem 3.12(ii), $f^{-1}(f(A))$ is $\gamma_{\mu}$-closed (as $f$ is $(\gamma, \beta)$-continuous) i.e., $A$ is $\gamma_{\mu}$-closed.

(ii) Let $B$ be a $\beta_{\lambda} g$-closed set of $(Y, \lambda)$. We have to show that $B$ is a $\beta_{\lambda}$-closed set. By Theorem 3.14(ii), $f^{-1}(B)$ is a $\gamma_{\mu} g$-closed set in $(X, \mu)$. Thus $f^{-1}(B)$ is $\gamma_{\mu}$-closed (as $(X, \mu)$ is $\left.\gamma_{\mu}-T_{1 / 2}\right)$. Thus from the assumption it follows that $B\left(=f f^{-1}(B)\right)$ is $\beta_{\lambda}$-closed in $(Y, \lambda)$. Thus it follows that $(Y, \lambda)$ is a $\beta_{\lambda}-T_{1 / 2}$ space.

(iii) The proof follows from (i) and (ii).

Theorem 3.16. Suppose that $f:(X, \mu) \rightarrow(Y, \lambda)$ is a $(\gamma, \beta)$-continuous bijection and $f^{-1}:(Y, \lambda) \rightarrow(X, \mu)$ is $(\beta, \gamma)$-continuous. Then $(X, \mu)$ is a $\gamma_{\mu}-T_{1 / 2}$ space if and only if $(Y, \lambda)$ is a $\beta_{\lambda}-T_{1 / 2}$ space.

Proof. Let $(X, \mu)$ be a $\gamma_{\mu}-T_{1 / 2}$ space. In view of Theorem 3.7 it is sufficient to show that any singleton set of $(Y, \lambda)$ is either $\beta_{\lambda}$-closed or $\beta_{\lambda}$-open. Let $\{y\}$ be any subset of $(Y, \lambda)$. Then, since $f$ is surjective, there exists $x \in X$ such that $f(x)=y$. Then by Theorem 3.7 it follows that $\{x\}$ is $\gamma_{\mu}$-closed or $\gamma_{\mu}$-open (as $(X, \mu$ ) is $\left.\gamma_{\mu}-T_{1 / 2}\right)$. Then by Theorem 3.12, $\{y\}(=f(\{x\}))$ is $\beta_{\lambda}$-closed or $\beta_{\lambda}$-open. Thus $(Y, \lambda)$ is a $\beta_{\lambda}-T_{1 / 2}$ space. The proof of the converse is similar.

Proposition 3.17. Let $f:(X, \mu) \rightarrow(Y, \lambda)$ be a $(\gamma, \beta)$-continuous injection and $(Y, \lambda)$ be a $\beta_{\lambda}-T_{2}\left(\right.$ resp. $\left.\beta_{\lambda}-T_{1}\right)$ space. Then $(X, \mu)$ is a $\gamma_{\mu}-T_{2}\left(\operatorname{resp} . \gamma_{\mu}-T_{1}\right)$ space.

Proof. Let $(Y, \lambda)$ be a $\beta_{\lambda}-T_{2}$ space. Let $x, y$ be any two points of $X$ with $x \neq y$. Then there exist $\lambda$-open sets $V$ and $W$ of $Y$ contaning $f(x)$ and $f(y)$ respectively such that $\beta_{\lambda}(V) \cap \beta_{\lambda}(W)=\varnothing$. Now by $(\gamma, \beta)$ continuity of $f$, there exist $\mu$-open sets $G$ and $H$ containing $x$ and $y$ respectively such that $f\left(\gamma_{\mu}(G)\right) \subseteq \beta_{\lambda}(V)$ and $f\left(\gamma_{\mu}(H)\right) \subseteq \beta_{\lambda}(W)$. Thus $\gamma_{\mu}(G) \cap \gamma_{\mu}(H)=\varnothing$. Thus $(X, \mu)$ is a $\gamma_{\mu}-T_{2}$ space.

The proof of the case of $\beta_{\lambda}-T_{1}$ can be done similarly.

Lemma 3.18. Let $\gamma_{\mu}: \mu \rightarrow \mathcal{P}(X)$ be a regular, $\mu$-open operation and $X \in \mu$. If $(X, \mu)$ is a $\gamma_{\mu}-T_{2}$ GTS, then $\left(X, \gamma_{\mu}\right)$ is a $T_{2}$ space.

Proof. We first note that since $\gamma_{\mu}: \mu \rightarrow \mathcal{P}(X)$ is regular and $X \in \mu$, by Theorem $2.9, \gamma_{\mu}$ is a topology on $X$. Let $x, y$ be two distinct points of $X$. Then there exist $\mu$-open sets $U$ and $V$ containing $x$ and $y$, respectively, such that $\gamma_{\mu}(U) \cap \gamma_{\mu}(V)=\varnothing$. Since $\gamma_{\mu}$ is $\mu$-open, there exist $\gamma_{\mu}$-open sets $U^{*}$ and $V^{*}$ containing $x$ and $y$, respectively, such that $U^{*} \subseteq \gamma_{\mu}(U)$ and $V^{*} \subseteq \gamma_{\mu}(V)$. Thus $U^{*} \cap V^{*}=\varnothing$ and $\left(X, \gamma_{\mu}\right)$ is a $T_{2}$ space.

Theorem 3.19. Let $\gamma_{\mu}: \mu \rightarrow \mathcal{P}(X)$ be a $\mu$-open regular operation and $\beta_{\lambda}: \lambda \rightarrow \mathcal{P}(Y)$ be a $\lambda$-open regular operation such that $X \in \mu$ and $Y \in \lambda$. If $f, g:(X, \mu) \rightarrow(Y, \lambda)$ are $(\gamma, \beta)$-continuous and $(Y, \lambda)$ is $\beta_{\lambda}-T_{2}$, then the set $A=\{x \in X: f(x)=g(x)\}$ is $\gamma_{\mu}$-closed in $(X, \mu)$.

Proof. We observe first by Lemma 3.18 that, $\gamma_{\mu}$ and $\beta_{\lambda}$ are two topologies on $X$ and $Y$, respectively. We shall now show that if $f:(X, \mu) \rightarrow(Y, \lambda)$ is $(\gamma, \beta)$-continuous, then $f:\left(X, \gamma_{\mu}\right) \rightarrow\left(Y, \beta_{\lambda}\right)$ is continuous. Let $x \in X$ and $V$ be any $\beta_{\lambda}$-open set containing $f(x)$. Then there exists a $\lambda$-open set $V^{\prime}$ such that $f(x) \in V^{\prime}$ and $\beta_{\lambda}\left(V^{\prime}\right) \subseteq V$. Since $f$ is $(\gamma, \beta)$-continuous, there exists a $\mu$-open set $W$ such that $x \in W$ and $f\left(\gamma_{\mu}(W)\right) \subseteq \beta_{\lambda}\left(V^{\prime}\right) \subseteq V$. Then by $\mu$-openness of $\gamma_{\mu}$ there exists a $\gamma_{\mu}$-open set $W^{\prime}$ containing $x$ such that $W^{\prime} \subseteq \gamma_{\mu}(W)$. Thus $f\left(W^{\prime}\right) \subseteq V$. Thus $f:\left(X, \gamma_{\mu}\right) \rightarrow\left(Y, \beta_{\lambda}\right)$ is continuous and similarly $g:\left(X, \gamma_{\mu}\right) \rightarrow\left(Y, \beta_{\lambda}\right)$ is continuous. By Lemma $3.18,\left(Y, \beta_{\lambda}\right)$ is a $T_{2}$ space. Therefore the set $A=\{x \in X: f(x)=g(x)\}$ is closed in $\left(X, \gamma_{\mu}\right)$ and hence $X \backslash A$ is $\gamma_{\mu}$-open. Thus $A$ is $\gamma_{\mu}$-closed in $(X, \mu)$.

\section{Acknowledgments}

The first author acknowledges the financial support from Department of Higher education, Science and technology and Biotechnology, Government of West Bengal, India. Also, the authors are thankful to the referee for some comments to improve the paper.

\section{References}

1 Kasahara, S. (1979). Operation-compact spaces, Math. Japon., 24, 97-105.

2 Janković, D. S. (1983). On functions with $\gamma$-closed graphs, Glasnik Mat., 18(38), 141-148.

3 Ogata, H., (1991). Operations on topological spaces and associated topology, Math. Japon., 36, $175-184$.

4 Krishnan, G. S. S., Ganster, M., \& Balachandran, K. (2007). Operation approaches on semi open sets and its application, Kochi J. Math., 2, 21-33.

5 Van An, T., Cuong, D. X., \& Maki, H. (2008). On operation-preopen sets in topological space, Sci. Math. Japon., 241-260. 
6 Császár, Á. (2002). Generalized topology, generalized continuity, Acta Math. Hungar., 96, 351-357.

7 Császár, Á. (2005). Generalized open sets in generalized topologies, Acta Math. Hungar., 106, 53-66.

8 Császár, Á. (2008). $\delta$ - and $\theta$-modifications of generalized topologies, Acta Math. Hungar., 120(3), 275-279.

9 Császár, Á. (2010). Weak structures, Acta Math. Hungar., 131, 193-195.

10 Zahran, A. M., El-Saady, K., \& Ghareeb, A. (2012). Modification of weak structures via hereditary classes, Applied Mathematics Letters, 25(5), 869-872.

11 Zahran, A. M., Musa, A. K., \& Ghareeb. A. (2015). Generalized closed sets and some separation axioms on weak structure Hacettepe Journal of Math. and Stat., 44(3), 669-677.

12 Ghareeb, A., \& Khalaf, M. M. (2015). On weak structures Analele Univ. Oradea Fasc. Mat., XXII(1), 129-134.

13 Ghareeb, A., \& Güldürdek, A. (2015). On modification of weak structures via hereditary classes, Bol. Soc. Paran. Mat., 35(1), 229-235.

14 Roy, B. (2010). On generalized $R_{0}$ and $R_{1}$ spaces, Acta Math. Hungar., 127, 291-300.

15 Roy, B. (2018). Applications on operations on minimal generalized open sets, Afrika Matematika, 29, 1097-1104.

\author{
Б. Рой${ }^{1}$, Т. Нуари ${ }^{2}$ \\ ${ }^{1}$ Әйелдер христиан колледжі, Калъкутта, Үндістан; \\ ${ }^{2}$ Яиусиро, ЖКапония
}

\title{
Жалпыланған топологиялық кеңістіктерге операцияларды қолдану
}

\begin{abstract}
Мақалада $\gamma_{\mu}$ - ашық жиындар және $\gamma_{\mu}$-GTS-тегі жабық жиындар $(X, \mu)$, мұнда $\gamma_{\mu}-\mu$-дан $\mathcal{P}(X)$-ға операция зерттелген. Жалпы, $\gamma_{\mu}$ - ашық жиындар жиынтығы $\mu$-ашық жиындар жиынтығынан аз. Сонымен қатар, авторлар екі жиын бірдей болатынын анықтаған. Мұндай жиындардың кейбір қасиеттері талқыланды. Сондай-ақ, жабу түрінің кейбір операторлары анықталып, олардың қасиеттері анықталды. GTS $(X, \mu)$-да ұқсас жабу операторларының түрлері арасында байланыс орнатылған. Белгілі бір тұйықталу түрінің операторы Куратовскийдің тұйықталу операторы болып табылатын шарт беріледі. Сондай-ақ, $\gamma_{\mu}$ деп аталатын жабық жиындардың жалпыланған түрі анықталғанжалпыланған жабық жиын, осы жаңадан анықталған жабу операторының көмегімен және осындай жиындардың кейбір негізгі қасиеттері талқыланған. Қосымша ретінде бөлімнің әлсіз аксиомалары енгізіліп, олардың кейбір қасиеттері талқыланды. Соңында осындай жалпыланған ұғымдарды сақтаудың кейбір теоремалары көрсетілген.
\end{abstract}

Kiлm сөздер: операция, $\mu$ - ашық жиын, $\gamma_{\mu}$ - ашық жиын, $\gamma_{\mu} g-$ жабық жиын.

\author{
Б. Рой${ }^{1}$, Т. Нуари ${ }^{2}$ \\ ${ }^{1}$ Женский христианский колледж, Калькутта, Индия; \\ ${ }^{2}$ Яиусиро, Япония
}

\section{Приложения операций над обобщенными топологическими пространствами}

\begin{abstract}
В статье изучены $\gamma_{\mu}$-открытые и $\gamma_{\mu}$-замкнутые множества в $\operatorname{GTS}(X, \mu)$, где $\gamma_{\mu}$ - операция из $\mu$ в $\mathcal{P}(X)$. В общем случае набор $\gamma_{\mu}$-открытых множеств меньше, чем набор $\mu$-открытых множеств. Кроме того, авторами установлено условие, при котором оба множества являются одинаковыми. Обсуждены и некоторые свойства таких множеств. Определены некоторые операторы типа замыкания и их свойства. Установлена связь между аналогичными типами операторов замыкания на GTS $(X, \mu)$. Дано
\end{abstract}


условие, при котором по-новому определенный оператор типа замыкания является оператором замыкания Куратовского. Выявлен обобщенный тип замкнутых множеств, названный $\gamma_{\mu}$-обобщенным замкнутым множеством, с помощью этого вновь определенного оператора замыкания и обсуждены некоторые основные свойства таких множеств. В качестве приложения авторами введены несколько слабых аксиом отделения и определены некоторые их свойства. Таким образом, показаны некоторые теоремы сохранения таких обобщенных понятий.

Ключевые слова: операция, $\mu$-открытое множество, $\gamma_{\mu}$-открытое множество, $\gamma_{\mu} g$-замкнутое множество.

\section{References}

1 Kasahara, S. (1979). Operation-compact spaces, Math. Japon., 24(1979), 97-105.

2 Janković, D. S. (1983). On functions with $\gamma$-closed graphs, Glasnik Mat., 18(38), 141-148.

3 Ogata, H.(1991). Operations on topological spaces and associated topology, Math. Japon., 36, $175-184$.

4 Krishnan, G. S. S. Ganster, M. \& Balachandran, K.(2007). Operation approaches on semi open sets and its application, Kochi J. Math., 2, 21-33.

5 Van An, T. Cuong D. X. \& Maki, H. (2008). On operation-preopen sets in topological space, Sci. Math. Japon., 241-260.

6 Császár, Á. (2002). Generalized topology, generalized continuity, Acta Math. Hungar., 96, 351-357.

7 Császár, Á.(2005). Generalized open sets in generalized topologies, Acta Math. Hungar., 106, 53-66.

8 Császár, Á.(2008). $\delta$ - and $\theta$-modifications of generalized topologies, Acta Math. Hungar., 120(3), $275-279$.

9 Császár, Á.(2010). Weak structures, Acta Math. Hungar., 131, 193-195.

10 Zahran A. M. El-Saady K. \& Ghareeb, A. (2012). Modification of weak structures via hereditary classes, Applied Mathematics Letters, 25(5), 869-872.

11 Zahran, A. M. Musa, A. K \& Ghareeb A. (2015). Generalized closed sets and some separation axioms on weak structure Hacettepe Journal of Math. and Stat., 44(3), 669 - 677.

12 Ghareeb, A. \& Khalaf M. M. (2015). On weak structures Analele Univ. Oradea Fasc. Mat., Tom XXII(1), $129-134$.

13 Ghareeb, A. \& Güldürdek, A. (2015). On modification of weak structures via hereditary classes, Bol. Soc. Paran. Mat., 35(1), 229-235.

14 Roy, B. (2010). On generalized $R_{0}$ and $R_{1}$ spaces, Acta Math. Hungar., (127), 291-300.

15 Roy, B. (2018). Applications on operations on minimal generalized open sets, Afrika Matematika, 29, 1097-1104. 